\title{
Feeding Ecology and Seasonal Changes in Food Habits of African Civet (Civettictis civetta, Schreber, 1776) In Aridtsy Forest, Western Ethiopia
}

\author{
Dessalew Shitu Ayene and Bekalu Melis Alehegn \\ Assosa University, College of Agriculture and Natural Resources, Ethiopia \\ E-mail: dessugold@gmail.com
}

\begin{abstract}
The feeding ecology of the African Civet was investigated in the Aridstey forest Awi zone, Amhara region of Ethiopia during August 2017January 2018. Food items were identified by the naked eye and unidentifiable food items of plants and animal matters were identified by using microscope. During the present investigation, 17 food items were identified from the fresh droppings of the African Civets. Out of these, the main animal feed items identified were insects, millipedes/centipedes. Cordia Africana, Ficus sp. and Zea mays were main plant items recorded. Feeding habits of civets change with season and on the availability of food. During the dry season, African Civets eat Cordia Africana and Ficus sp., in high proportion. During the wet season, millipedes/centipedes and insects largely contributed for food. During both this seasons, insects, rodents and grasses were commonly observed as food items of civets. The scent markings were the height of $32-39 \mathrm{~cm}$ above the ground and the civets scent marked mostly on Eucalyptus sp., Clausenia anisata and Capsicum annuum.
\end{abstract}

Keywords: African Civet, Civetry sites, Food habits, Scent marking, Civettictis civetta, Aridtsy forest

Ethiopia is located in the Horn of Africa within the tropics and is a relatively-vast country with a land area of 1.12 million square kilometers with a wide variety of topography and climatic patterns. There is a great variation in altitude ranges of different areas in Ethiopia, ranging from $116 \mathrm{~m}$ below sea level in the Danakil depression to $4620 \mathrm{~m}$ asl at the top of Ras Dashen. The great plains of Ethiopia lie along two massive highland plateaus, observed in the middle by the Great Rift Valley. Much of the interior of Ethiopia is dominated by highland plateaus, and are home to numerous endemic species of flora and fauna (Worku and Bale-Robe, 2019). Ethiopia is the home of diverse wild animal species, some of which are endemic. There are over 288 species of mammals in Ethiopia (Worku and Bale-Robe, 2019). Civets are distributed widely, not only limited in natural habitats but also found in villages, farmlands and human surroundings (Balakrishnan and Sreedevi, 2007). African civets are larger and more dog-like than the small Indian Civet (Viverricula indica). African Civets tend to be most active just after sunset and tend to hunt in areas that provide plenty of cover. Civets do not possess carransial teeth, and are known to be omnivorous, eating fruits and carrion as well as a wide variety of small vertebrates and invertebrates. African Civet has a varied diet that consists of both animal and plant matters. They feed on snail, insects, millipedes, centipedes, birds, rodents and plant matters such as fruits with seeds (Morrongiello et al 2008). A study in Menegasha-Suba state
Forest, Ethiopia revealed the most common food items of the Civets were meat of small animals such as rodents and birds, fruits of Ficus and Maytenus, millipedes, centipedes and insects. The diet also varied seasonally, based on the availability of food items (Morrongiello et al 2008).

\section{MATERIAL AND METHODS}

Study sites; For this study three habitat types were selected such us, plantation, natural forest and agricultural habitats. To study feeding ecology and seasonal changes both wet season August to October, 2017 and dry season November, 2017 to January 2018 data were incorporated. Fresh fecal samples were collected from the civetries and dried by sunlight, crushed in a mortar and washed using hot water to separate undigested materials in the feces such as, hairs, bones, cuticles of millipedes and other prey components. Separated materials were washed in acetone, dehydrated in $100 \%$ ethanol and dried on filter papers. Then it was observed under a stereomicroscope for identity. From each of the study habitats, three study sites were chosen based on their distance from the civetry. These sites were checked for 15 days/month for fresh droppings. Scent marked locations were also observed and assessed for frequency of marking. Perineal glandular secretions were removed from the scent marked sites to check whether the Civets remark on the same location, on the same object. The objects that were scent marked, path of marking and the color change of the "civet" were recorded. 
During the present investigation to identify the food items of the African Civet, fresh droppings from civetries during both wet and dry seasons were collected. The droppings were checked for undigested food items such as, seeds, leaves, grass blades, shells, feather, hair and bone. The size and texture of the droppings were estimated to identify age groups of African Civet by using the method of Putman and Wratten (1984). The faces of young and adult African Civets were shown in (Fig. 1). The faces size of adult was large and the young were small. The population estimation of Civets in this study area was also made by counting the fresh droppings recorded.

Scent markings: The information was recorded from the scent marked objects: height of the object at which the marks were laid, GPS location, the color of the markings, the distance of the objects to the nearest latrine sites. All plants on which scent mark were located were identified.

Quadrats: To identify the preference of scent marking of the Civet on a specific plant species, quadrats of $5 \times 5 \mathrm{~m} 2$ were laid in different parts of study areas. Based on the proximity to site, the quadrat was laid in the site by following the methods of (Sutherland 2006). Each plant species in the quadrat was counted.

Data analysis: Data analysis was performed by SPSS version 15 , computer software to estimate the population variation and the food items from fresh droppings of African Civet.

\section{RESULTS AND DISCUSSION}

\section{African Civet Population different Land Habitat}

Forest: The population estimate of the African civet in the forest habitat was 5.38 per 60 hectare and the population density was 0.089 / hectare. Out of the total, 2.053 were young and 3.13 were adults (Table 1). The largest and the smallest number of adults were registered in December and in October respectively and largest and the smallest number of young was in November and December respectively. There was monthly variation of the counts of both the adult

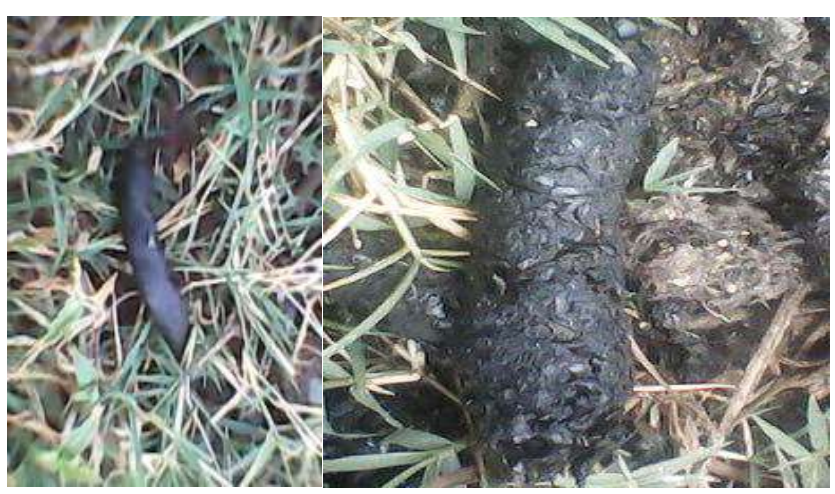

Fig. 1. Faeces of a young African Civet on the left and adult on the right sides (Photo by author; September 2017) and the young $(x 2=29.42)$ and $(x 2=812$,), respectively. The number of young declined from 3 during the wet season to 2.2 during the dry season. The number of adults increased marginally from 2.99 during the wet season to 5.88in the dry season. Over all, total of adult African Civet population in both seasons in forest habitat was significance The highest number of young was in November, being 3.33 of the population and this young African civet showed significance within months. The least number of young African Civets were in December and varied significantly within seasons. The total of adult African Civet population in both seasons forest habitat was significant.

Plantation habitat: The population estimate of the African Civet in the plantation habitat was 4.77 per 20 hectares. The population density in the plantation habitat was $0.238 /$ hectare. Out of these, the young contributed for 1.33and adults for 3.6 (Table 2). The maximum number of young were in December and the least was in August during wet and dry season. In this habitat, the total number of young African civets population in increased from 1.22 in the wet season to 1.44 in the dry season. There was more adults Civets in the plantation habitat in September and the least number was in January with significant difference. In this habitat, the total number of adult African civets population was significant and was 3.99 and 5.54 in wet and dry seasons.

Farm land habitat: The population estimate of the African Civet in the farmland habitat was 4.65 per 10 hectare and the population density was 0.465 per hectare (Table 3 ). Highest number of adult African Civet was recorded in January (5.6)

Table 1. African civet population in the forest habitat during wet and dry seasons

\begin{tabular}{llccc}
\hline Season & Month & Young & Adult & Total \\
\hline \multirow{4}{*}{ Wet } & August & $2.33 \pm .57$ & $3.33 \pm 1.57$ & $5.66 \pm 2.14$ \\
& September & $1.66 \pm .57$ & $4.33 \pm 2.08$ & $5.99 \pm 2.65$ \\
& October & $1.66 \pm 1.15$ & $1.33 \pm .57$ & $2.99 \pm 1.72$ \\
\multirow{3}{*}{ Dry } & November & $3.33 \pm 1.15$ & $2.66 \pm 1.15$ & $6.99 \pm 2.3$ \\
& December & $1.33 \pm .57$ & $5 \pm 2.64$ & $6.33 \pm 3.21$ \\
Mean & January & $2 \pm 1$ & $2.33 \pm 1.52$ & $4.33 \pm 2.52$ \\
& & $2.05 \pm .83$ & $3.13 \pm 1.58$ & $5.38 \pm 2.42$ \\
\hline
\end{tabular}

Table 2. African civet population in the plantation habitat

\begin{tabular}{llccc}
\hline Season & Month & Young & Adult & Total \\
\hline Wet & August & $1 \pm 1$ & $1.66 \pm .7$ & $2.66 \pm 1.7$ \\
& September & $1.33 \pm .57$ & $5 \pm 1$ & $5.33 \pm 1.57$ \\
& October & $1.33 \pm 1.15$ & $2.66 \pm .57$ & $3.99 \pm 1.72$ \\
Dry & November & $1.33 \pm .57$ & $2.33 \pm .57$ & $3.66 \pm 1.14$ \\
& December & $1.66 \pm 1.15$ & $3.33 \pm 1.52$ & $4.99 \pm 2.67$ \\
& January & $1.33 \pm 1.52$ & $6.66 \pm .57$ & $7.99 \pm 2.09$ \\
Mean & & $1.33 \pm .99$ & $3.60 \pm .82$ & $4.77 \pm 1.81$ \\
\hline
\end{tabular}


and the least in November (1.33), with a significant difference. The population of the adult African Civets exhibited significant difference season's number increased from 2.22 during wet season to 3.19 during the dry season. The highest number of young African Civets was observed in January and young civets were not recorded in September in the farm land habitat. There were significant variation in the number of young Civets observed different months.

Food items of the African Civet: During the present investigation, a total of 17 different food items were identified from the droppings collected from civetries (Table 4). These food items were found in different proportions. A total of 467 food components were recorded from the samples of Civet droppings analyzed. These components belonged to 17 food categories. Even if the proportion of each these food items were different from sample to sample, all items were found in all habitats from the samples of droppings were collected for the study.

Food items in the droppings of African civets: Among the food items identified, insects formed a large proportion, (15.2 $\%$ ) and the least consumed food item was Sorghum vulgar, (1.49\%). Seasonally, insects and Sorghum vulgar (showed significantly increased intake by civets.

Forest habitat during the wet season: During the wet season Civets in the forest habitat consumed more of insects (21\%), followed by millipedes and centipedes $(20.51 \%)$ and the least consumed food item was hen (5.13\%) (Table 5). Significant variation was observed based on seasonality of insects and hen food. But there was no significant variation in the consumption of millipedes/centipedes with the reference to season (20.51\%).

Forest habitat during the dry season: Civets consumed mostly Cordia africana (17.77 \%) and Ficus sur (14.44\%) and the least consumed food item was Eleusine coracana (3.33\%) (Table 6). However, there was no significant variation in the consumption of Cordia africana and Ficus sur with in seasons. However, the intake of Eleusine coracana showed significant variation within seasons.

Plantation habitat during wet season: During the wet season, in the plantation habitat, most frequently consumed food items were insects $(25.71 \%)$ followed by rodents (22.85) and the least consumed food items were Solanum tuberosum and birds ( 2.85 and $5.71 \%$, respectively) (Table 7 ). Significant variation was observed in the consumption of insects, Solanum tuberosum and birds within season. No significant variation was observed in the consumption of rodents within season.

Plantation habitat during the dry season: In the plantation habitat, most frequently consumed feed items were Cordia africana, and Zea mays which accounted for $15.0 \%$ and
Table 3. African civet population in the farmland habitat

\begin{tabular}{llccc}
\hline Season & Month & Young & Adult & Total \\
\hline Wet & August & $1.66 \pm .57$ & $3 \pm 1$ & $4.66 \pm 1.57$ \\
& September & - & $2.33 \pm 1.52$ & $2.33 \pm 1.52$ \\
& October & $1.33 \pm .57$ & $3.33 \pm .57$ & $4.66 \pm 1.14$ \\
\multirow{4}{*}{ Dry } & November & $2 \pm 1$ & $1.33 \pm 1.52$ & $3.33 \pm 2.52$ \\
& December & $1.66 \pm .57$ & $2.66 \pm 2.08$ & $4.32 \pm 2.65$ \\
& January & $3 \pm 1$ & $5.6 \pm .57$ & $8.6 \pm 1.57$ \\
Mean & & $1.93 \pm .72$ & $3.04 \pm 0.95$ & $4.65 \pm 1.82$ \\
\hline
\end{tabular}

Table 4. Percentage of food items observed in the droppings of African Civet

\begin{tabular}{lcc}
\hline Food items & Number of observations & Per cent \\
\hline Zea mays & 26 & 5.56 \\
Eleusine coracana & 11 & 2.35 \\
Eragrostis teff & 12 & 2.56 \\
Capsicum annuum & 28 & 5.99 \\
Sorghum vulgar & 7 & 1.49 \\
Cordia africana & 42 & 8.99 \\
Ficus vasta & 35 & 7.49 \\
Insects & 71 & 15.2 \\
Ficus sur & 35 & 7.49 \\
Cyprus rigidifolius & 32 & 6.85 \\
Ensete venntricosum & 28 & 5.99 \\
Rodents hair and bone & 48 & 10.27 \\
Millipedes/centipides & 42 & 8.99 \\
Hen head & 12 & 2.56 \\
Bird feather & 11 & 2.35 \\
Solanum tuberosum & 7 & 1.49 \\
Snail & 20 & 4.28 \\
Total & 467 & 100 \\
\hline
\end{tabular}

Table 5. Percentage of food items observed in the droppings of African civet in forest habitat during the wet season

\begin{tabular}{lcc}
\hline Food items & No. of observations & Percent \\
\hline Millipedes and centipedes & 16 & 20.51 \\
Rodents hair and bone & 13 & 16.66 \\
Snail & 7 & 8.97 \\
Hen head & 4 & 5.13 \\
Bird feather & 5 & 6.41 \\
Insects & 21 & 26.92 \\
Cyprus rigidifolius & 8 & 10.25 \\
Solanum tuberosum (Potato) & 4 & 5.13 \\
Total & 78 & 100 \\
\hline
\end{tabular}


Table 6. Percentage of food items observed in the droppings of African civet in the forest habitat during the dry season

\begin{tabular}{lcc}
\hline Food items & No. of observations & Percent \\
\hline Zea mays & 8 & 8.88 \\
Eleusine coracana & 3 & 3.33 \\
Eragrostis teff & 5 & 5.55 \\
Capsicum annuum & 8 & 8.88 \\
Sorghum vulgar & 4 & 4.44 \\
Cordia africana & 16 & 17.77 \\
Ficus vasta & 10 & 11.11 \\
Insects & 7 & 7.77 \\
Ficus sur & 13 & 14.44 \\
Cyprus rigidifolius & 4 & 4.44 \\
Ensete venntricosum & 8 & 8.88 \\
Rodents hair and bone & 4 & 4.44 \\
Total & 90 & 100 \\
\hline
\end{tabular}

Table 7. Percentage of food items of African civet at plantation during wet season

\begin{tabular}{lcc}
\hline Food items & No. of observations & Percent \\
\hline Millipedes and centipedes & 14 & 20 \\
Rodents hair and bone & 16 & 22.85 \\
Snail & 5 & 7.14 \\
Hen head & 5 & 7.14 \\
Bird feather & 4 & 5.71 \\
Insects & 18 & 25.71 \\
Cyprus rigidifolius & 6 & 8.57 \\
Solanum tuberosum & 2 & 2.85 \\
Total & 70 & 100 \\
\hline
\end{tabular}

$13.75 \%$ respectively. Elusine coracana was the least consumed food item (2.5\%) (Table 8 ). There were no variation among the highest and the least consumed food items within the season, Cordia Africana, Zea mays and Elusine coracana.

Agricultural habitat during the wet season: In the farmland habitat, during the wet season, most frequently consumed food items were insects, which constituted for $26.22 \%$, followed by millipedes and centipedes $19.67 \%$ and the least were covered of hen and Solanum tuberosum (4.91and 1.63 $\%$, respectively (Table 9 ). Significance was observed in the consumption of insects and hen within the season. There was no variation in the consumption of millipedes/centipedes and Solanum tuberosum within the season.

Agricultural habitat during the dry season: In the agricultural habitat, 12 food items were identified during dry season from the fresh droppings of African Civet. Out of these dominantly consumed food items were Cordia africana and
Table 8. Food items of the African civet in the plantation habitat during the dry season

\begin{tabular}{lcc}
\hline Food items & No. of observations & Percent \\
\hline Zea mays & 11 & 13.75 \\
Eleusine coracana & 2 & 2.5 \\
Eragrostis teff & 3 & 3.75 \\
Capsicum annuum & 9 & 11.25 \\
Sorghum vulgar & 2 & 2.5 \\
Cordia africana & 12 & 15 \\
Ficus vasta & 12 & 15 \\
Insects & 4 & 5 \\
Ficus sur & 10 & 12.5 \\
Cyprus rigidifolius & 3 & 3.75 \\
Ensete venntricosum & 9 & 11.25 \\
Rodents hair and bone & 3 & 3.75 \\
Total & 80 & 100 \\
\hline
\end{tabular}

Table 9. Food items of African Civet in the agricultural habitat during the wet season

\begin{tabular}{lcc}
\hline Food items & No. of observations & Percent \\
\hline Millipedes and centipedes & 12 & 19.67 \\
Rodents hair and bone & 10 & 16.39 \\
Snail & 8 & 13.11 \\
Hen bone and feather & 3 & 4.91 \\
Bird feather & 2 & 3.27 \\
Insects & 16 & 26.22 \\
Cyprus rigidifolius & 9 & 14.75 \\
Solanum tuberosum & 1 & 1.63 \\
Total & 61 & 100 \\
\hline
\end{tabular}

Table 10. Food items of African Civet in the agricultural habitat during the dry season

\begin{tabular}{lcc}
\hline Food items & No. of observations & Percent \\
\hline Zea mays & 7 & 7.95 \\
Eleusine coracana & 6 & 6.81 \\
Eragrostis teff & 4 & 4.54 \\
Capsicum annuum & 11 & 12.5 \\
Sorghum vulgar & 1 & 1.14 \\
Cordia Africana & 14 & 15.9 \\
Insects & 5 & 5.68 \\
Ficus vasta & 13 & 14.77 \\
Ficus sur & 12 & 13.63 \\
Cyprus rigidifolius & 2 & 2.27 \\
Ensete venntricosum & 11 & 12.5 \\
Rodents hair and bone & 2 & 2.27 \\
Total & 88 & 100 \\
\hline
\end{tabular}


Table 11. African Civet defecation during both the wet and the dry seasons

\begin{tabular}{lccccc}
\hline & \multicolumn{3}{c}{ No. of days with droppings } \\
\cline { 2 - 5 } & \multicolumn{2}{c}{ Wet season } & & \multicolumn{3}{c}{ Dry season } \\
\cline { 2 - 5 } \cline { 5 - 6 } & Number & Percent & & Number & Percent \\
\hline Number of days with defecation & 23 & 51.11 & 24 & 53.33 \\
Number of days without defecation & 22 & 48.88 & & 21 & 46.66 \\
Total & 45 & 100 & & 45 & 100 \\
\hline
\end{tabular}

Ficus vasta. These food items constituted for 15.9 and $14.77 \%$, respectively (Table 10). Least consumed food items were Sorghum vulgar (1.14 \%), and rodents $(2.27 \%)$. The consumption of Cordia africana, Ficus vasta and Sorghum vulgarnot varied within the season.

Seasonality in the feeding of civets: During the wet season, eight food items were identified from the droppings of the African Civets in the present study area. Out of the 17 food items identified from the droppings in both seasons, the food items were not observed during the wet season were Zea mays, Eleusina coracana, Eragrostis teff, Sorghum vulgar, Capsicum annuum, Cordia africana, Ficus vasta, Fius sur and Ensete venntricosum. During the dry season, millipedes/centipedes, Solanum tuberosum, snail, hen and birds were not found in the droppings of the African Civet. The three food items (grass, insects and rodents) were consumed during both the dry and the wet seasons.

Defecation rate during the dry and the wet seasons: Out of the 45 days of observations on civetries there were 23 days when fresh droppings were observed during the wet season whereas during the dry season, there were fresh droppings on 24 days (Table 11). The frequency of defecation was high during the dry season and the amount and types of food were also observed in high proportion during the dry season than during the wet season.

\section{CONCLUSION}

During the present investigation, 17 food items of African
Civets were identified from the Aridtsey forest, in Ethiopia which is unprotected area. Civets depended on the availability of different food items seasonally. Present investigation analyzes that marking frequency and the amount of faeces varied with the season.

\section{REFERENCES}

Balakrishnan M and SreedevI M 2007. Husbandry and management of the Small Indian Civet Viverricula indica (É. Geoffroy Saint-Hilaire 1803) in Kerala, India. Small Carnivore Conservation 36: 9-13.

Ewer R and Wemmer C 1974. The behaviour in captivity of the African civet, Civettictus civetta (Schreber). Zeitschrift für Tierpsychologie.

Feldpausch TR, Lloyd J, Lewi SSL, Brienen RJ, Gloor M, Monteagudo Mendoza A, Lopez-Gonzale ZG, Banin L, Abu Salim K and Affum-Baffo EK 2012. Tree height integrated into pantropical forest biomass estimates. Biogeosciences 9: 33813403.

Kumar MA, Mudappa D and Raman TS 2010. Asian elephant Elephas maximus habitat use and ranging in fragmented rainforest and plantations in the Anamalai Hills, India. Tropical Conservation Science 3: 143-158.

Morrongiell O BA, Cusimano M, Orr E, Barton B, Chipman M, Tyberg J, Kulkarini A, Khanlou N, Masi R and Bekele T 2008. Schoolage children's safety attitudes, cognitions, knowledge, and injury experiences: How do these relate to their safety practices? Injury Prevention 14: 176-179.

Putman R and Wratten SD 1984. Principles of ecology, Univ of California Press.

Sutherland WJ 2006. Ecological census techniques: A handbook, Cambridge university press.

Worku D and Bale-Rob EE 2019. Impacts of Wildlife on the Livelihood of Communities Living Near Protected Areas in Ethiopia, Control Measures and Its Implication for Conservation. 